Maxiselly, Y. • D. Ustari · A. Ismail · A. Karuniawan

\title{
Pola penyebaran tanaman jengkol (Pithecellobium jiringa (Jack) Prain.) di Jawa Barat bagian selatan berdasarkan karakter morfologi
}

\author{
Distribution pattern of jengkol plant (Pithecellobium jiringa (Jack) \\ Prain.) in south of West Java based on morphological trait
}

\author{
Diterima : 15 Februari 2016/Disetujui : 1 Maret 2016 / Dipublikasikan : Maret 2016 \\ CDepartment of Crop Science, Padjadjaran University
}

\begin{abstract}
The southern area of West Java has the potential of natural resources are abundant. One of commodity that has the potential to be developed in the south of West Java is a jengkol (Pithecellobium Jiringa (Jack) Prain.). This study aimed to obtain data on the spread pattern jengkol plant in the southern part of West Java. The study was conducted from November to December 2013. The location survey was including several regions in Ciamis, Tasikmalaya and Garut using the method of determining the location of exploration and purposive sampling. Data were collected for morphological traits with in situ characterization methods. The results showed that based on principal component analysis (PCA) were random distribution patterns or no specific area on accessionaccession jengkol collected from the south of West Java. There are 3 accession jengkol namely JG3, JG7 and JG10 were clustered in contrast to another accessions due to the shape of flowers, flower position, and the circumference of the fruit which is the most character jengkol contribute to variations in the southern part of West Java.
\end{abstract}

Keywords : Principle component analysis . Jengkol · Purposive sampling

Sari Jawa Barat bagian selatan memiliki potensi sumber daya alam yang berlimpah. Salah satu komoditas yang berpotensi dikembangkan di Jawa Barat bagian selatan adalah tanaman

\footnotetext{
Dikomunikasikan oleh Fiky Yulianto Wicaksono

Maxiselly, Y. ${ }^{1} \cdot$ D. Ustari ${ }^{2} \cdot$ A. Ismail ${ }^{3} \cdot$ A. Karuniawan ${ }^{3}$

${ }^{1}$ Staf pengajar di Laboratorium Produksi Tanaman

Faperta UNPAD Bandung

${ }^{2}$ Alumnus Agroteknologi Faperta UNPAD Bandung

${ }^{3}$ Staf pengajar di Laboratorium Pemuliaan Tanaman

Faperta UNPAD Bandung

Korespondensi : yudithia.maxiselly@unpad.ac.id
}

jengkol (Pithecellobium Jiringa (Jack) Prain.). Penelitian ini bertujuan untuk memperoleh data mengenai pola penyebaran tanaman jengkol di Jawa Barat bagian selatan. Penelitian dilakukan dari bulan November sampai bulan Desember 2013. Lokasi survey meliputi beberapa desa di kabupaten Ciamis, kabupaten Tasikmalaya, dan kabupaten Garut dengan menggunakan metode eksplorasi dan penentuan lokasi secara purposive sampling. Pengamatan dilakukan terhadap karakter morfologi dengan metode karakterisasi in situ. Hasil penelitian menunjukkan bahwa berdasarkan Analisis Komponen Utama (Principle Component Analysis) terdapat pola penyebaran yang acak atau tidak spesifik wilayah pada aksesi-aksesi jengkol yang dikoleksi dari Jawa Barat Selatan. Terdapat 3 aksesi jengkol yaitu JG 3, JG 7 dan JG 10 yang mengelompok berbeda dengan aksesi-aksesi jengkol yang lain diakibatkan karakter bentuk bunga, posisi bunga, dan lingkar buah yang merupakan karakter paling berkontribusi pada variasi jengkol di Jawa Barat bagian Selatan.

Kata kunci: Analisis komponen utama · Jengkol - Purposive sampling

\section{Pendahuluan}

Jengkol (Pithecellobium jiringa (Jack) Prain.) adalah salah satu tanaman hortikultura yang digunakan sebagai bahan pangan masyarakat Indonesia. Manfaat lainnya, jengkol dapat dijadikan tanaman obat, kompos, dan pestisida nabati. Salah satu penyakit yang dipercaya dapat dicegah dengan mengkonsumsi jengkol adalah diabetes mellitus. Bagian cangkang, biji dan kulit batang jengkol memiliki kandungan zat anti diabetes (Evacusiany dkk, 2004). Tanaman jengkol yang popular sebagai bahan 
pangan ternyata juga memiliki berbagai potensi yang dapat diperluas kegunaannya. Jengkol termasuk keluarga polong-polongan dan merupakan tanaman asli dari Asia Tenggara. Tanaman jengkol dapat tumbuh dengan baik di daerah dengan curah hujan yang sedang. Buahnya berupa polong, bentuknya gepeng berbelit membentuk spiral dan berwarna coklat kehitaman (Sastrapraja, 2012).

Daerah pemasok jengkol adalah Sumatera Utara, Jawa Barat, Jawa Tengah dan Kalimantan Barat. Jawa Barat bagian selatan merupakan produsen jengkol untuk Provinsi Jawa Barat. Jawa Barat bagian selatan memiliki potensi sumber daya alam yang berlimpah, salah satu komoditas yang dikembangkan adalah tanaman jengkol. Pengembangan jengkol di Jawa Barat bagian selatan meliputi kabupaten Ciamis, kabupaten Tasikmalaya dan kabupaten Garut (Kompas, 2013). Namun belum terdapat perkebunan jengkol berskala besar, jengkol baru dikembangkan orang per orang dalam bentuk kebun atau sekedar ditanam di pekarangan rumah (home garden) (Republika, 2013). Perlu dilakukan kegiatan eksplorasi untuk mengetahui potensi jengkol disetiap daerah di Jawa Barat bagian selatan.

Kegiatan eksplorasi merupakan dasar untuk menentukan lokasi yang memiliki sumber daya alam yang berpotensi untuk dimanfaatkan selanjutnya. Hasil eksplorasi tentu akan menjadi deskripsi awal potensi daerah dan objek eksplorasi. Eksplorasi dapat dilakukan di hutanhutan, daerah yang belum dikembangkan masyarakat atau juga di wilayah-wilayah yang sudah dipelihara masyarakat namun belum dalam skala besar contohnya di kebun koleksi pribadi atau pekarangan rumah yang biasa dikenal dengan home garden (Taber, 2013). Eksplorasi juga merupakan kegiatan yang mampu meningkatkan variabilitas sehingga dapat memperkaya sumber genetik yang dapat dikembangkan lebih lanjut.

Pengembangan individu dapat dimulai dengan mengetahui pola penyebarannya. Pola penyebaran individu di daerah bermanfaat untuk menyusun strategi pelestarian individu yang diteliti (Maxiselly, 2011). Pola penyebaran ini dapat dianalisis berdasarkan karakter morfologi untuk menentukan pemanfaatan plasma nutfah yang dikarakterisasi. Menurut Setyowati dkk, (2007) plasma nutfah dapat dimanfaatkan apabila sifat tanaman tersebut diketahui. Identifikasi karakter juga digunakan sebagai indikator yang signifikan untuk gen yang spesifik dan penanda gen dalam kromo-som karena sifat-sifat yang mempengaruhi morfologi dapat diturunkan (Sofro, 1994). Pola penyebaran dianalisis melalui Principle Compo-nent Analysis (PCA) atau Analisis Komponen Utama yang juga dapat menilai sejauh mana kontribusi suatu karakter terhadap penampilan fenotipik tanaman jengkol.

Penelitian ini adalah langkah untuk mencari plasma nutfah tanaman jengkol untuk pengembangan jengkol yang berkualitas baik berdasarkan karakter morfologi, sehingga masyarakat khususnya Jawa Barat bagian selatan akan mengembangkan jengkol yang berkualitas untuk meningkatkan nilai ekonomisnya.

\section{Bahan dan Metode}

Penelitian dilaksanakan pada bulan November Desember 2013. Daerah lokasi pengamatan yaitu kabupaten Ciamis, kabupaten Garut, dan kabupaten Tasikmalaya. Cara pemilihan lokasi berdasarkan wawancara pedagang di Pasar Induk Caringin dan Pasar Induk Gede Bage di Kota Bandung. Lokasi pengamatan merupakan representasi Jawa Barat bagian selatan.

Bahan yang digunakan yaitu populasi tanaman jengkol yang ditemukan di lokasi pengamatan. Alat yang digunakan pada penelitian yaitu Global Positioning System (GPS) untuk mengetahui koordinat dan ketinggian tempat, meteran, galah untuk mengait buah jengkol, kamera digital untuk alat dokumentasi, alat tulis, dan kuesioner yang digunakan pada saat wawancara dengan pemilik tanaman jengkol di lokasi pengamatan.

Metode penelitian menggunakan metode survey dan eksplorasi tempat dengan penentuan lokasi secara purposive sampling. Pengamatan karakter terdiri dari pengamatan berupa karakter morfologi tanaman jengkol yang ditemui pengamatan keragaman berupa pengamatan tanaman jengkol pada daerah-daerah yang diamati. Pengamatan dilakukan dengan skoring karakter menggunakan deskriptor rambutan yang dimodifikasi IPGRI (International Plant Genetic Resources Institute) pada tahun 2003 dikarenakan deskriptor untuk tanaman jengkol belum tersedia.

Analisis komponen utama (PCA) digunakan untuk mencari karakter mana yang memberikan nilai kontribusi tinggi dan 
mempengaruhi variasi pada tanaman jengkol yang diamati. Analisis komponen utama ini dianalisis berdasarkan 19 karakter morfologi terhadap 36 aksesi jengkol yang dikarakterisasi. Karakter-karakter yang diamati berupa karakter kuantitatif dan kualitatif. Karakter kualitatif berupa bentuk dasar daun, bentuk ujung daun, bentuk pangkal daun, warna batang, susunan ranting, posisi bunga, bentuk bunga, bentuk buah, warna cangkang luar, warna cangkang dalam, dan warna biji, sedangkan karakter kuantitatif meliputi panjang daun, lebar daun, lingkar batang, lingkar buah, lingkar biji, jumlah buah per tangkai, jumlah spiral per tangkai dan jumlah buah per spiral.

\section{Hasil dan Pembahasan}

Pengamatan tanaman jengkol di Jawa Barat dilakukan pada 36 titik pengamatan. Titik pengamatan tersebut diambil dari 3 kabupaten, yaitu kabupaten Ciamis, kabupaten Tasikmalaya, dan kabupaten Garut. Tiga lokasi yang dipilih kemudian diklasifikasikan berdasarkan ketinggian tempat yaitu dataran rendah (0-499 meter dpl), medium (500-1000 meter dpl), dan tinggi (>1000 meter dpl) (Natawijaya dkk., 2009). Berdasarkan hasil survey, tanaman jengkol ditemukan di semua ketinggian tempat (Tabel 1).

Tabel 1 menunjukan bahwa tanaman jengkol yang tumbuh di beberapa titik pengamatan di kabupaten Ciamis yaitu pada dataran rendah terdapat 1 aksesi dan dataran medium yaitu 24 aksesi sementara tidak diperoleh aksesi jengkol pada dataran tinggi. Satu aksesi diperoleh pada dataran rendah, 2 aksesi pada dataran medium dan 1 aksesi pada dataran tinggi di kabupaten Tasikmalaya. Pengamatan di kabupaten Garut diperoleh 8 aksesi pada dataran medium, tidak diperoleh aksesi pada dataran rendah maupun dataran tinggi.

Tanaman jengkol dapat tumbuh pada semua ketinggian tempat. Hal ini meng- gambarkan bahwa genotip jengkol beradaptasi tinggi, namun yang banyak ditemukan di lokasi pengamatan adalah tanaman jengkol pada dataran medium. Tanaman jengkol ini dapat diasumsikan memang paling cocok ditanam pada dataran medium.

Pengaruh nilai variasi dan nilai eigenvalue dari hasil analisis komponen utama tercantum pada Tabel 2. Variasi yang terjadi karena pengaruh karakter yang diamati mencapai $86,65 \%$ pada PC4, sedangkan sisanya merupakan pengaruh dari faktor lain.

Tabel 2. Eigenvalue dan Variability pada Populasi Jengkol.

\begin{tabular}{cccc}
\hline \hline PC & Eigenvalue & $\begin{array}{c}\text { Variability } \\
\text { \% }\end{array}$ & $\begin{array}{c}\text { \% } \\
\text { Kumulatif }\end{array}$ \\
\hline 1 & 3.83 & 42.58 & 42.58 \\
2 & 1.59 & 17.65 & 60.23 \\
3 & 1.51 & 16.76 & 76.99 \\
4 & 0.87 & 9.66 & 86.65 \\
\hline \hline
\end{tabular}

Keterangan : PC merupakan kombinasi linear dari beberapa variabel dan berhubungan dengan satu dimensi.

Menurut Afuape dkk (2011), kontribusi suatu karakter terhadap keragaman dapat diketahui melalui PCA. Pengaruh pengelompokkan sebesar $42.58 \%$ yang terdapat pada PC1 menunjukan karakter yang paling berkontribusi pada aksesi jengkol adalah posisi bunga, bentuk bunga dan lingkar buah. Pada PC2 yang berkontribusi $17.65 \%$ dengan karakter yang berpengaruh yaitu bentuk ujung daun dan warna batang. Pada PC3 nilai variasi sebesar $16.77 \%$ karakter yang berkontribusi adalah lebar daun dan pada PC4 sebesar $9.66 \%$ karakter yang paling berpengaruh adalah lingkar batang (Tabel 2).

Hasil PCA menunjukan tabel yang menjelaskan karakter-karakter yang berkontribusi pada variasi 36 aksesi tanaman jengkol. Nilai vektor matrik 19 karakter pada populasi tanaman jengkol tercantum pada Tabel 3.

Tabel 1. Penyebaran Tanaman Jengkol Berdasarkan Ketinggian Tempat.

\begin{tabular}{|c|c|c|c|c|c|c|}
\hline \multirow{2}{*}{$\begin{array}{l}\text { Daerah Asal } \\
\text { Tanaman } \\
\text { Jengkol }\end{array}$} & \multicolumn{2}{|c|}{$\begin{array}{c}\text { Rendah } \\
(<500 \text { mdpl })\end{array}$} & \multicolumn{2}{|c|}{$\begin{array}{c}\text { Medium } \\
\text { (500-1000 mdpl) }\end{array}$} & \multicolumn{2}{|c|}{$\begin{array}{c}\text { Tinggi } \\
(>1000 \text { mdpl) }\end{array}$} \\
\hline & Lokasi & $\begin{array}{l}\text { Jumlah } \\
\text { Aksesi }\end{array}$ & Lokasi & $\begin{array}{l}\text { Jumlah } \\
\text { Aksesi }\end{array}$ & Lokasi & $\begin{array}{l}\text { Jumlah } \\
\text { Aksesi }\end{array}$ \\
\hline Ciamis & 1 & 1 & 24 & 24 & - & - \\
\hline Tasikmalaya & 1 & 1 & 2 & 2 & 1 & 1 \\
\hline Garut & - & - & 8 & 8 & - & - \\
\hline
\end{tabular}


Tabel 3. Nilai Vektor Matrik 19 Karakter pada Populasi Jengkol.

\begin{tabular}{lllll}
\hline \hline \multicolumn{1}{c}{ Karakter } & PC 1 & PC 2 & PC 3 & PC 4 \\
\hline Bentuk dasar daun & 0.000 & 0.000 & 0.000 & 0.000 \\
Bentuk ujung daun & 0.022 & $\mathbf{0 . 6 5 4}$ & 0.004 & 0.090 \\
Bentuk pangkal daun & 0.487 & 0.035 & 0.287 & 0.096 \\
Warna batang & 0.003 & $\mathbf{0 . 6 0 7}$ & 0.063 & 0.105 \\
Susunan ranting & 0.000 & 0.001 & 0.013 & 0.331 \\
Posisi bunga & $\mathbf{0 . 9 1 1}$ & 0.018 & 0.003 & 0.006 \\
Bentuk bunga & $\mathbf{0 . 9 1 1}$ & 0.018 & 0.003 & 0.006 \\
Bentuk buah & 0.000 & 0.000 & 0.000 & 0.004 \\
Warna cangkang luar & 0.000 & 0.000 & 0.000 & 0.000 \\
Warna cangkang & & & & \\
dalam & 0.000 & 0.000 & 0.000 & 0.000 \\
Warna biji & 0.000 & 0.000 & 0.000 & 0.000 \\
Panjang daun & 0.010 & 0.295 & 0.478 & 0.017 \\
Lebar daun & 0.098 & 0.078 & $\mathbf{0 . 6 0 6}$ & 0.009 \\
Lingkar batang & 0.028 & 0.284 & 0.003 & $\mathbf{0 . 6 6 8}$ \\
Lingkar buah & $\mathbf{0 . 6 8 5}$ & 0.124 & 0.020 & 0.016 \\
Lingkar biji & 0.218 & 0.381 & 0.139 & 0.003 \\
Jumlah buah per & & & & \\
tangkai & 0.488 & 0.125 & 0.171 & 0.046 \\
Jumlah spiral per & & & & \\
tangkai & 0.000 & 0.000 & 0.000 & 0.000 \\
Jumlah buah per & & & & \\
spiral & 0.483 & 0.266 & 0.086 & 0.097 \\
\hline \hline Keterangan Angka yang & & & & \\
\hline
\end{tabular}

Keterangan : Angka yang dicetak tebal merupakan nilai karakter yang berpengaruh karena diskriminant $>0.5$ atau < - 0,5 (Zubair, 2004).

Berdasarkan Tabel 3, terdapat 7 karakter yang berkontribusi pada variasi 36 aksesi tanaman jengkol. Karakter tersebut adalah posisi bunga, bentuk bunga dan lingkar buah. Posisi bunga memiliki nilai 0.911 , bentuk bunga 0.911 dan lingkar buah 0.685. Menurut Zubair (2004), nilai karakter berpengaruh pada variasi jenis karena diskriminan $>0.5$ atau $<-0.5$. Pada komponen kedua (PC2) karakter yang berpengaruh adalah karakter bentuk ujung daun dan warna batang. Masing-masing nilai dari karakter tersebut adalah 0.654 dan 0.607. Pada komponen ketiga (PC3) dan keempat (PC4) karakter yang berkontribusi pada variasi jengkol adalah lebar daun dan lingkar batang dengan masing-masing nilai dari karakter tersebut yaitu 0.606 dan 0.668 . Tidak terdapat nilai diskriminan yang $<-5$ pada PC1, PC2, PC3 maupun PC4. Karakter yang memiliki diskriminan $>0,5$ berarti memiliki pengaruh positif terhadap variasi genetik (Maxiselly $d k k$, 2008). Pada Tabel 3 dapat terlihat bahwa beberapa karakter yang berkontribusi memiliki nilai diskriminan $>0,5$, karakter bernilai $>0,5$ menandakan karakter yang berpengaruh terhadap hubungan kekerabatan.

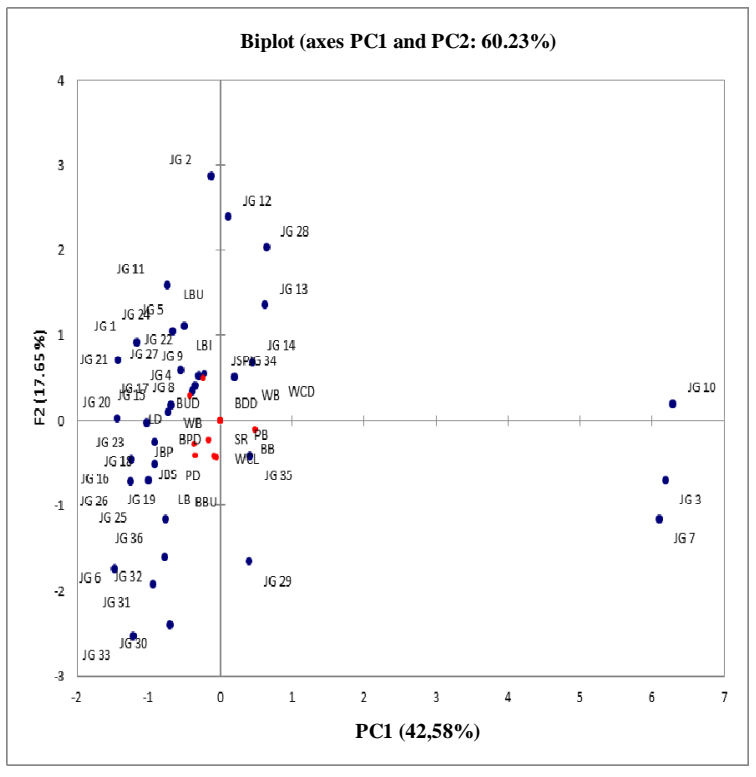

Keterangan :Bentuk Dasar Daun (BDD), Bentuk Ujung Daun (BUD), Bentuk Pangkal Daun (BPD), Warna Batang (WB), Susunan Ranting (SR), Posisi Bunga (PB), Bentuk Bunga (BB), Bentuk Buah (BBU), Warna Cangkang Luar (WCL), Warna Cangkang Dalam (WCD), Warna Biji (WB), Panjang Daun (PD), Lebar Daun (LD), Lingkar Batang (LB), Lingkar Buah (LBU), Lingkar Biji (LBI), Jumlah Buah per Tangkai (JBP), Jumlah Spiral per Tangkai (JSP), Jumlah Buah per Spiral (JBS).

\section{Gambar 1. Grafik Biplot Tanaman Jengkol di Semua Lokasi Pengamatan.}

Gambar 1 menunjukan grafik biplot yang terbentuk memiliki nilai kontribusi genetik $60,23 \%$ sedangkan sisanya yang berasal dari pengaruh lingkungan sebesar $39,27 \%$ belum tergambar pada grafik biplot tersebut. Hasil yang dapat dilihat bahwa kuadran 1 terdiri dari 6 aksesi yaitu dari kabupaten Ciamis ( JG 13, JG 14, dan JG 28), kabupaten Tasikmalaya (JG 10 dan JG 12), dan kabupaten Garut (JG 34). Karakter yang mempengaruhi berkumpulnya aksesi pada kuadran ini, yaitu bentuk dasar daun, warna cangkang dalam, warna biji, dan jumlah spiral per tangkai.

Kuadran 2 terdiri dari 14 aksesi dari kabupaten Ciamis (JG 1, JG 2, JG 4, JG 5, JG 8, JG 15, JG 17, JG 20, JG 21, JG 22, JG 24, dan JG 27), dan kabupaten Tasikmalaya (JG 9 dan JG 11). Karakter yang mempengaruhi berkumpulnya aksesi pada kuadran ini, yaitu bentuk ujung daun, lingkar buah dan lingkar biji. Dua belas aksesi terdapat pada kuadran III yang terdiri dari asal kabupaten Ciamis (JG 6, JG 16, JG 18, JG 19, JG 23, JG 25 dan JG 26) dan kabupaten 
Garut (JG 30, JG 31, JG 32, JG 33, dan JG 36). Karakter yang mempengaruhinya adalah karakter bentuk pangkal daun, warna batang, bentuk buah, panjang daun, lingkar batang, jumlah buah per tangkai dan jumlah buah per spiral. Empat aksesi dari kabupaten Ciamis (JG 3 dan JG 7) dan kabupaten Garut (JG 29 dan JG 35) terdapat pada kuadran IV. Karakter yang mempengaruhinya adalah susunan ranting, posisi bunga, bentuk bunga dan warna cangkang luar. Grafik biplot tersebut menunjukan pola penyebaran tanaman jengkol yang acak berdasarkan latar belakang daerah. Penyebaran non spesifik tersebut memiliki arti tanaman jengkol memungkinkan tersebar luas di daerahdaerah Jawa Barat Selatan lainnya dengan karakter yang sama pada aksesi yang diuji. Menurut Karuniawan dkk (2010) pola penyebaran juga dipengaruhi iklim, keadaan tanah, organisme lain juga campur tangan manusia.

Grafik biplot juga dapat menjelaskan kedekatan morfologi antar aksesi jengkol. Aksesi JG 3, JG 7 dan JG 10 tampak terpisah dari kelompok. Tiga aksesi ini sedang dalam fase berbunga dan belum berbuah seperti aksesi yang lain pada saat pengamatan sehingga ada beberapa karakter seperti bentuk buah, warna cangkang luar, warna cangkang dalam, warna biji, lingkar buah, jumlah buah per tangkai, jumlah spiral per tangkai dan jumlah buah perspiral tidak dapat dikarakterisasi pada aksesi JG 3, JG 7 dan JG 10. Hal ini dapat diasumsikan bahwa 3 aksesi ini merupakan jenis tanaman jengkol yang berbeda dengan aksesi yang lain dilihat dari fase pertumbuhannya. Keragaman penampilan tanaman akibat perbedaan susunan genetik selalu mungkin terjadi sekalipun tanaman yang digunakan berasal dari jenis yang sama (Sitompul dan Guritno, 1995). Aksesi jengkol JG 3, JG 7 dan JG 10 dapat diasumsikan memiliki perbedaan karakter morfologi yang jauh dengan aksesi jengkol lainnya.

\section{Kesimpulan}

Berdasarkan Principle component analysis pada grafik biplot terdapat pola penyebaran yang acak atau tidak spesifik wilayah pada aksesiaksesi jengkol yang dikoleksi dari Jawa Barat Selatan. Terdapat 3 aksesi jengkol yaitu JG 3, JG 7 dan JG 10 yang mengelompok berbeda dengan aksesi-aksesi jengkol yang lain. Karakter yang paling mempengaruhi variasi adalah posisi bunga, bentuk bunga, dan lingkar buah.

\section{Ucapan Terima Kasih}

Penelitian ini di danai oleh Hibah Kompetitif Universitas Padjadjaran Tahun 2013.

\section{Daftar Pustaka}

Afuape S. O., Okocha P. I. dan Njoku D. 2011. Multivariate assessment of the agromorphological variability and yield components among sweetpotato (Ipomoea batatas (L.) Lam) landraces. Afr. J. Plant Sci. 5(2), 123-132

Evacuasiany E, H. William, dan S. Santosa. 2004. Pengaruh Biji Jengkol (Pithecellobium jiringa) terhadap Kadar Glukosa Darah Mencit Galur Balb/c. JKM. Vol. 4, No 1.

International Plant Genetic Resources Institute (IPGRI). 2003. Descriptors for Rambutan (Nephelium lappaceum). IPGRI.

Karuniawan P.W, E. Murniyanto, and N. Nakagoshi. 2010. Distribution Of Edibles Wild Taro (Aroid Plant) On The Different Altitude (Shoutern Slope Of Wonogiri And Pacitan). Agrivita Volume 32 No. 3

Kompas, 2013. Lampaui harga daging ayam jengkol hilang di pasar tasikmalaya. Diakses dari http://tekno.kompas.com/ read/2013/06/04/1703143/lampaui. harga.daging.ayam.jengkol.hilang.di.pasar. tasikmalaya. Pada 20 Oktober 2013.

Maxiselly, Y. 2011. Keragaman dan Pola Penyebaran talas spesies Colocasia esculenta dan Xanthosoma sagittifolium di Jawa Barat. Tesis. Universitas Padjadjaran.

Maxiselly, Y., D. Ruswandi dan A. Karuniawan. 2008. Penampilan Fenotipik, Variabilitas, dan Hubungan Kekerabatan 39 Genotip Genus Vigna dan Phaseolus berdasarkan Sifat Morfologi dan Komponen Hasil. Zuriat Vol.19 No.2.

Mustafa, H. 2000. Teknik Sampling. Tidak dipublikasikan.

Natawijaya, A, A. Karuniawan, dan C. Bakti. 2009. Eksplorasi dan analisis kekerabatan Amorphopallus blume Ex. Decaisne di sumatera barat. Zuriat Vol. 20 No.2

Republika. 2013. Jengkol hilang dipasaran sejak sepekan terakhir. Diakses dari http:// www.repbublika.co.id/berita/nasional/ja wa-barat nasional/13/06/08/ mo2ini- 
jengkol-hilanh-di-pasaran-sejak-sepekanterakhir pada 28 September 2013.

Sastrapraja S. 2012. Perjalanan Panjang Tanaman Indonesia. Yayasan Pustaka Obor Indonesia. Jakarta.

Setyowati, M., I. Hanarida, dan Sutoro. 2007. Karakteristik umbi plasma nutfah talas (C. esculenta). Bul. Plasma Nutfah Vol 13 No.2.

Sitompul, S. M., dan B. Guritno. 1995. Analisis Pertumbuhan Tanaman. Gadjah Mada University Prees. Yogyakarta.
Sofro, A.S.M. 1994. Keanekaragaman Genetik. Yogyakarta: Andi Offset.

Taber, H.G,. 2013. Planting a home vegetable garden. ISU Extension Horticulture. Diakses dari http://www.extension.iastate.edu/ publicatuios/pm819.pdf pada 20 Oktober 2013.

Zubair, M. 2004. Genetic Diversity and Gene Action in Mungbean. Thesis. Faculty of Crop and Food Sciences. University of Arid Agriculture, Rawalpindi. Pakistan. 